\section{A bioética como contributo no tratamento das mordeduras de serpentes peçonhentas}

\section{Francisco, António Hélder Manuel}

Doutorando em Bioética /UnB. Coordenador para área científica da Faculdade de Medicina de Malanje.Helderhumilde@gmail.com

PALAVRAS-CHAVE: Conhecimento tradicional; plantas medicinais; bioética; saúde pública.

Introdução: $\mathrm{O}$ homem no processo de aculturação aprende e apreende tacitamente, pré-reflexivamente, os modos de viver e o manuseio dos instrumentos necessários para fazer a vida social possível. $\mathrm{O}$ conhecimento se incorpora espontaneamente à vida e forma parte dela em estreita relação com os modos de sentir e querer, constituindo um sistema de saber rico e multilateral. A cultura humana, desde a modernidade, tem tido um de seus centros na ciência e no conhecimento científico. Com o avanço científico e tecnológico, a sociedade do conhecimento deixou de ser uma quimera e, embora o desempenho científico apresente manifestações sumamente contraditórias, tem ocorrido grandes ganhos e avanços do saber, novos instrumentos de trabalho, maior independência do homem com respeito a diversos fatores naturais, desenvolvimento da medicina e a produção de novas tecnologias capazes de reproduzir a vida, protegê-la e conservá-la, novas potencialidades produtivas e de construção social. Objetivo: Identificar os critérios da população de comunidades expostas a risco de mordeduras de serpentes peçonhentas acerca das práticas tradicionais e médicas para o tratamento das mesmas. Caracterizar os conhecimentos e opiniões de profissionais de saúde e da biomedicina sobre o tratamento da mordedura de serpentes peçonhentas. Métodos: Diante desses olhares, pretendeu-se investigar quais os critérios que as populações expostas a riscos de mordeduras de serpentes peçonhentas perante as práticas tradicionais e convencionais tratam sob o olhar dos profissionais da saúde e a comunidade tradicionais. A pesquisa de caráter qualitativo e de abordagem fenomenológica. No entanto, estes indicam que não abandonarão o uso das plantas, pois em algum momento o soro pode não estar disponível, uma vez que, o acesso e tratamento no sistema público de saúde é incipiente ou inexistente. Compreendem ainda que não há interesse do estado para esse problema de saúde. Resultado: Os resultados e a discussão advêm das falas dos participantes, analisando-se, de forma geral, os procedimentos utilizados, por um lado, pelos profissionais da saúde diante de um acidente ofídico e o ponto de vista deles sobre a utilização das plantas medicinais dentro e fora dos hospitais e, por outro lado, os métodos usados pelo pessoal da comunidade e seus procedimentos para o mesmo fim. $\mathrm{O}$ trabalho também foi analisado e lido utilizando os aportes da Bioética de
Intervenção para a discussão. Ressalta-se em especial os "4 pés" e os referenciais dos artigos 12 e 14 da Declaração Universal sobre Bioética e Direitos Humanos, sendo que o último destes, enfatiza que a promoção da saúde e do desenvolvimento social da população deve ser o objeto central dos governos, partilhado por todos os setores da sociedade. Considerações finais: Assim, o estudo contribuirá para abrir um diálogo na comunidade científica, considerando a Bioética de intervenção para a abordagem do tema em questão, o qual está relacionado a conflitos entre duas formas de tratamento para a mordedura de serpentes. A Bioética é fundamental para a abordagem e reflexão de temas que podem gerar conflitos éticos que envolvem a cultura e o modo de viver de localidades e países distintos, considerando a vulnerabilidade e o impacto social que esta pode criar.

AGRADECIMENTO: Ao Programa de Pós-Graduação em Bioética da Universidade de Brasília, especialmente ao professor Volnei Garrafa por ter aceite que eu fizesse parte deste programa, em mim depositando sua confiança de que seria capaz, muito mais pela atitude do que por palavras. Ao professor José Ramon Acosta Sariego pelos valiosos ensinamentos sobre Bioética, tanto que, mesmo não entendendo bem a princípio, com o tempo fui tomando gosto pelo assunto.

\section{REFERÊNCIAS}

[1] LORENZO, CFG. Desafios para uma Bioética clínica interétnica: reflexões a partir da política nacional de saúde indígena. Revista Bioética. 2011;19(2): 331-337.

[2] OLIVEIRA, PRS. Serpentes em Angola: uma visão toxinológica e clínica dos envenenamentos. Lisboa/Portugal: Glaciar; 2017.

[3] SILBERMAN, RPS. Biotecnología y antivenenos: el caso de África. Biotecnologia, v, 14: IBt - UNAM. 2007:3.

[4] GARRAFA, V. Introdução à Bioética. Revista do Hospital Universitário, Universidade Federal do Maranhão, UFMA. 2005;6(2): 1-13.

[5] UNESCO. Declaração Universal sobre Bioética e Direitos Humanos. Tradução brasileira da Cátedra Unesco de Bioética da Universidade de Brasília (UnB). 